Revista Eletrônica em Gestão, Educação e Tecnologia Ambiental

Santa Maria, v. 20, n. 1, jan.-abr. 2016, p. 148-161

REGET/UFSM

Revista do Centro de Ciências Naturais e Exatas - UFSM

ISSN : 22361170

\title{
A APLICABILIDADE DO ICMS ECOLÓGICO NOS MUNICÍPIOS PARANAENSES
}

\author{
The Applicability of ICMS-e $e^{1}$ in Paraná State municipalities (Brazil)
}

\section{Joelma Leopoldino Aguirre², Vilma Nogueira ${ }^{3}$, Paulinho Rene Stefanello4, Alexandre Machado Fernandes ${ }^{5}$, Frederico Fonseca da Silva ${ }^{6}$}

${ }^{2}$ Acadêmica do curso Bacharelado em Ciências Contábeis do IFPR - Instituto Federal do Paraná.

${ }^{3}$ Acadêmica do curso Bacharelado em Ciências Contábeis do IFPR - Instituto Federal do Paraná

${ }^{4}$ Professor e Pesquisador do IFPR, M.Sc. em Sustentabilidade e Governança.

${ }_{5}^{5}$ Professor e Pesquisador do IFPR, M.Sc. em Administração.

${ }^{6}$ Professor e Pesquisador do IFPR, Doutor em Meio ambiente.

\section{Resumo}

O ICMS Ecológico é um importante instrumento de Política Pública voltada ao Meio Ambiente, compensando financeiramente municípios paranaenses que possuem em seu território Áreas de Preservação Ambiental elou Mananciais de Abastecimento Público. O objetivo geral deste estudo consistiu em verificar a aplicabilidade dos recursos nos municípios beneficiados pela receita advinda do ICMS-e no Estado do Paraná. A metodologia se fundamenta na revisão bibliográfica e documental, e entrevistas com servidores públicos municipais e estaduais, das áreas fiscal e ambiental. Constatou-se através das pesquisas, baixo percentual de aplicação do ICMS-e em ações voltadas à preservação ambiental, mesmo em municípios altamente dependentes desta fonte de receitas para sua manutenção. Sugerem-se ações de educação ambiental $e$ conscientização do poder público municipal com a inserção na LDO e na LOA de parcela significativa e suficiente dos recursos gerados pelo Meio Ambiente em programas e ações efetivas para a preservação e manutenção ambiental.

Palavras-chave: ICMS, ICMS Ecológico, enquadramento, benefícios e aplicabilidade.

\section{Abstract}

The ICMS-e $e^{1}$ is an important instrument of public politics focused to environment, compensating financially cities of Parana state (Brazil) that have in their territory Environmental Preservation Areas and / or Water Source Public Supply. The general purpose of this study was verifying the applicability of resources in the municipalities benefit from income derived from the ICMS in the State of Parana. The methodology is based on bibliographic and documentary review and interviews with state and local public officials, fiscal and environmental areas. It was found through research low percentage of application of ICMS-e on actions focused at environmental preservation, even in municipalities highly dependent of this source of revenue for your maintenance. It is suggested environmental education and awareness of the municipal government with the inclusion in the Budget Guidelines Law (LDO) and Annual Budget Law (LOA) of significant and sufficient part of the resources generated by the environment programs and effective actions for the preservation and environmental maintenance.

Keywords: ICMS, ICMS-e, framework, benefits and applicability

\footnotetext{
${ }^{1}$ ICMS-e: The ecological tax on merchandise and services, used and applied in Brazil.
} 


\section{INTRODUÇÃO}

A preocupação com o meio ambiente nas últimas décadas tem sido motivo de amplas discussões em Conferencias Internacionais, entre elas a Convenção de Estocolmo 1972 (BRASIL, 1972), Rio de Janeiro 1992 (OLIVEIRA, 2012), Rio +10 (DINIZ, 2002), Rio +20 (BRASIL, 2012), Protocolo de Kyoto 1998 (BRASIL, 1999), nas quais foram gerados Acordos e Tratados Internacionais visando à proteção do Meio Ambiente, a recuperação de áreas degradadas e a preservação de áreas ainda conservadas, combater o efeito estufa provocado pela destruição da camada de ozônio causado pela emissão de poluentes gasosos, o uso desenfreado dos recursos naturais, a escassez e a poluição da água pela emissão de efluentes domésticos, industriais e agrotóxicos, além da devastação da biodiversidade.

Segundo Freitas (2006), biodiversidade significa: "bio" - vida, e "diversidade" variedade, dessa forma Biodiversidade, ou Diversidade Biológica abrange a todas as variedades de formas de vida encontradas na Terra.

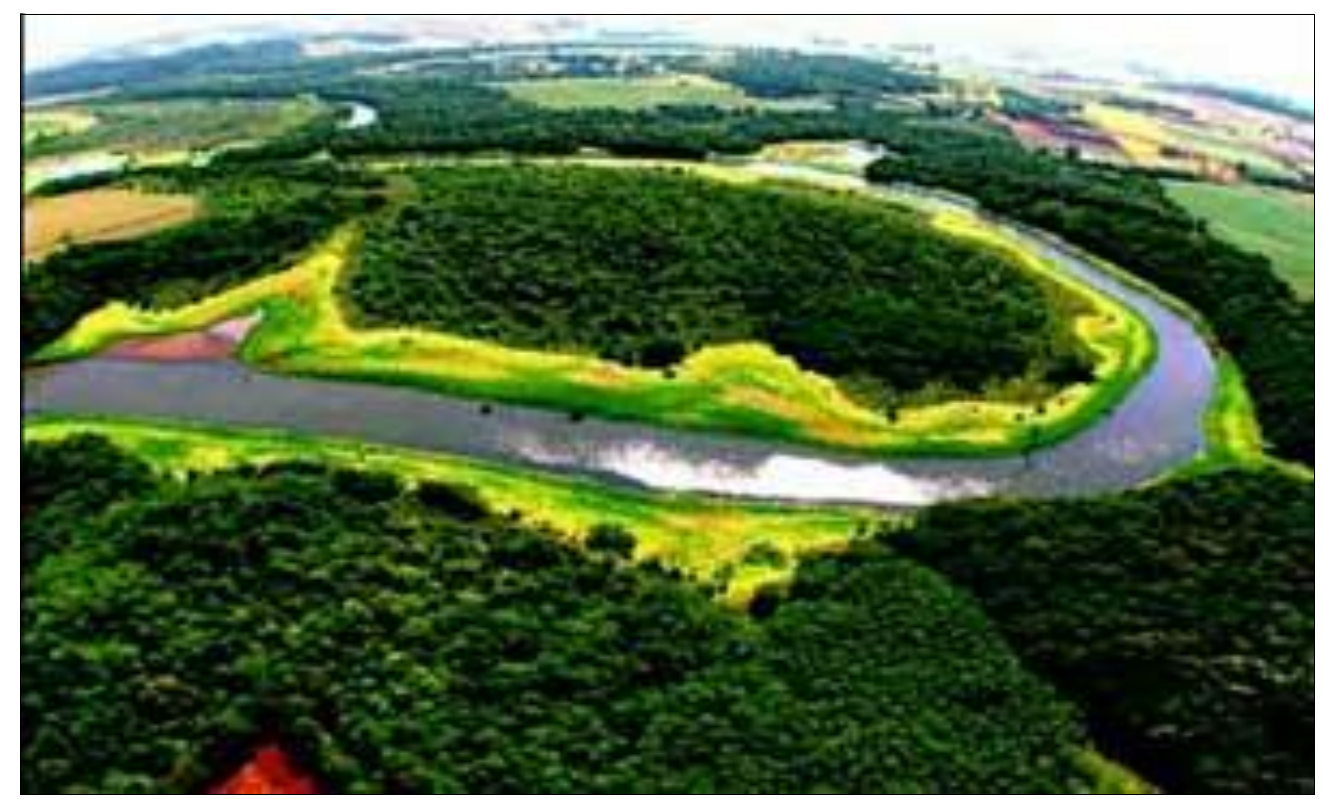

Figura 1. Biodiversidade. (Adaptado de DANTAS, 2010).

A partir da consciência ecológica despertada com a realização das Conferencias Internacionais, uma extensa legislação foi desenvolvida no país, dentre elas a Lei Federal 6.938/81 (BRASIL, 1981) que dispõe sobre a Política Nacional do Meio Ambiente, posteriormente recepcionada pela CF 1988 (GOMES e DOMINGOS, 2013; BRASIL, 1988); a Lei Federal 9.985/2000 que institui o Sistema Nacional de Unidades de Conservação divida em dois grupos: as Unidades de Proteção Integral e as Unidades de Uso Sustentável (BRASIL, 2000), Lei 12.187/2009 (BRASIL, 2009), institui a Política Nacional sobre Mudança do Clima, Lei Complementar 59/1991 (IAP, 1991), do Estado do Paraná, que institui o ICMS Ecológico, e ainda o Projeto de Lei 792/2007 que tramita no Congresso Nacional que pretende instituir a Política Nacional de Pagamentos por Serviços Ambientais (WWF-Brasil, 2014), entre outras, que visam à proteção do Meio Ambiente para as presentes e futuras gerações, e preveem a participação do Estado e da Sociedade como um todo. 
Nesse sentido, procurou-se identificar as condições necessárias para a obtenção do beneficio e as formas de aplicação dos recursos financeiros oriundos do ICMS Ecológico e ampliar as discussões sobre o tema, proporcionando esclarecimentos sobre as formas de obtenção do enquadramento à Lei e a destinação dada pelos municípios aos recursos oriundos do repasse financeiro do ICMS Ecológico pelo Estado.

\section{METODOLOGIA}

A pesquisa bibliográfica descritiva e exploratória foi realizada a partir da analise da Constituição Federal do Brasil de 1988, da Constituição do Estado do Paraná, e das legislações Federal e Estadual vigentes sobre ICMS, ICMS Ecológico e Meio Ambiente no que concerne a áreas de preservação e mananciais.

Realizou-se também entrevistas com servidores públicos Municipais e Estaduais das áreas ambientais e tributárias, consulta a divulgações oficiais do Instituto das Águas do Paraná e do Instituto do Meio Ambiente do Estado, órgãos competentes para regulamentar a matéria, assim como artigos científicos, periódicos além de jornais e revistas, por meio da truncagem das palavras chave: ICMS Ecológico, políticas públicas, enquadramento e benefícios, dentre outras similares.

\section{O ESTADO DO PARANÁ}

O Paraná foi o primeiro estado a adotar uma legislação voltada para o Meio Ambiente, denominada de ICMS Ecológico, por meio da aprovação e publicação da Lei Complementar no 59/1991 (IAP, 1991) datada de 1o outubro de 1991.

Trata-se de um instrumento de política pública que visa o repasse de recursos como compensação financeira aos municípios que possuem áreas de mananciais para abastecimento próprio e de municípios vizinhos, e áreas de conservação ambiental em seu território (IAP, 20[??]) nas quais são impossibilitados ou limitados na exploração econômica.

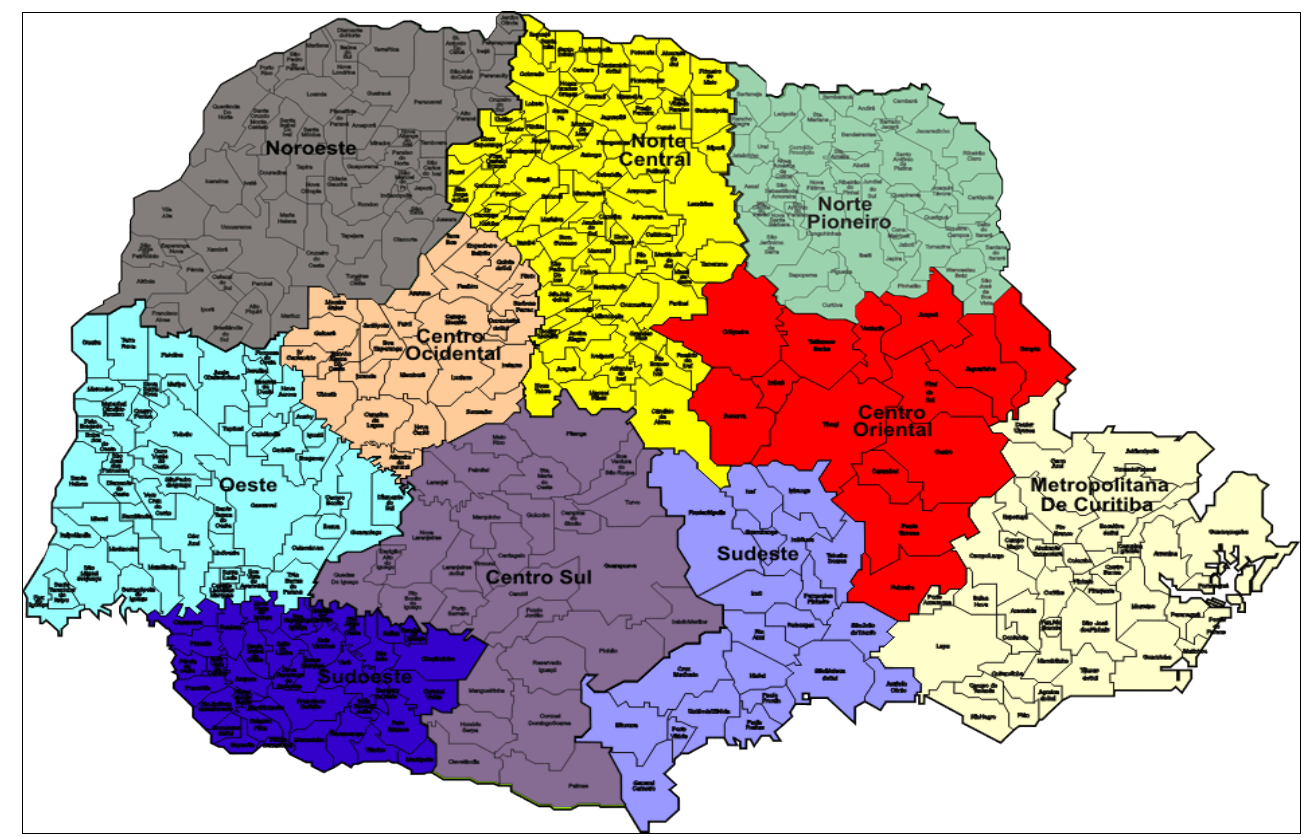

Figura 2. Mapa do Estado do Paraná. (Adaptado de: MAPASDOMUNDO, 2013). 
O Paraná é um dos vinte e seis estados brasileiros, situado na região sul do país, possui uma área territorial de 199.307,945 km² distribuídas pelos 399 municípios que o compõem, abrigando uma população estimada em 11.081.692 habitantes segundo dados divulgados pelo IBGE (2014) onde, dos municípios, 241 são beneficiados com o ICMS Ecológico, sendo 82 com áreas de Mananciais de Abastecimento; e, 200 com áreas de Unidades de Conservação, dentre os quais, 41 municípios possuem Mananciais e Unidades de Conservação em sua extensão territorial (SEMA, 2014).

\subsection{Imposto Sobre Circulação de Mercadorias e Serviços - ICMS}

O ICMS é um imposto não vinculado (aquele em que o fato gerador ocorre independente da atividade do estado, mediante a ocorrência da circulação de mercadorias e serviços), não cumulativo (compensando-se o que for devido em cada operação relativa à circulação de mercadorias ou prestação de serviços com o montante cobrado nas anteriores pelo mesmo ou outro estado ou pelo Distrito Federal), de competência dos estados e do Distrito Federal e está contido no Art. 155, Caput II, IV $\S 2^{\circ}$, I da CF (BRASIL, 1988), e regulamentado pela Lei Complementar no 87/1996 (BRASIL, 1996).

O valor da alíquota do ICMS varia de estado para estado, cada qual com sua própria tabela de alíquotas, sendo de competência dos estados sua instituição ou alteração mediante aprovação pelo Poder Legislativo, no seu artigo 6ํㅡ (CTN, 2010).

Usa-se como critério a essencialidade dos produtos e serviços, tributando com percentuais menores os produtos de primeira necessidade e alíquotas maiores os produtos tidos como supérfluos, conforme Constituição Federal, art. 153 (BRASIL, 1988).

De acordo com o Artigo 158, Inciso IV, da Constituição Federal (BRASIL, 1988), do montante arrecadado pelo ICMS estadual e do Distrito Federal, relativas à circulação de mercadorias e sobre prestações de serviços de transporte interestadual e intermunicipal e de comunicação realizados em seus territórios.

Cabe aos municípios $25 \%$, sendo que desse percentual, 3/4 no mínimo, ou $75 \%$ deve ser distribuído aos municípios na proporção do $\mathrm{VAF}^{7}$ (correspondente ao valor das saídas de mercadorias acrescidos das prestações de serviços no seu território, deduzindo-se o valor das entradas de mercadorias em cada ano civil), e os outros $1 / 4(25 \%)$ de acordo com o que dispuser a Lei Estadual (BRASIL, 1988), conforme Quadro 1:

Quadro 1. Critérios de partilha da Quota-Parte dos municípios no ICMS, nos estados federados.

\begin{tabular}{|l|l|}
\hline PARANÁ & $\%$ \\
\hline Valor Adicionado & 75,0 \\
\hline Valor da Produção Agropecuária & 8,0 \\
\hline População Rural & 6,0 \\
\hline Áreas de Preservação & 2,5 \\
\hline Áreas e Qualidades de Mananciais & 2,5 \\
\hline Área & 2,0 \\
\hline No de Propriedades Rurais & 2,0 \\
\hline Linear & 2,0 \\
\hline
\end{tabular}

(Adaptado de AGM, 2013).

\footnotetext{
${ }^{7}$ VAF - Valor Adicionado Fiscal
} 


\subsection{ICMS Ecológico}

Antecipando-se aos demais estados, e vindo de encontro aos anseios e expectativas provocados pelos Tratados e Acordos Internacionais que estabelecem metas a serem atingidas pelos países signatários, o Paraná criou o ICMS Ecológico, legislação especifica para compensar as perdas de receitas provocadas pela criação de áreas de preservação dos ecossistemas e mananciais nos municípios em cujas áreas protegidas há limitação e em algumas situações a proibição para a instalação de indústrias ou exploração por atividades agroindustriais, restringindo o desenvolvimento econômico dos municípios (LOUREIRO, 1997).

Trata-se da Lei Complementar Estadual no 59/1991 (IAP, 1991), regulamentada pelo Decreto Estadual no 974/1991, reformulada pelo Decreto Estadual nº 2.791/1996 (PARANÁ, 1996), que destinou $5 \%$ do total do ICMS arrecadado pelo estado aos municípios, sendo $2,5 \%$ aos municípios com mananciais de abastecimento público, e outros 2,5\% para municípios que tenham integrado em seu território Unidades de Conservação (UC), Áreas de Terras Indígenas (ATIs), Reservas Particulares do Patrimônio Natural (RPPN) regulamentada pelo Decreto no 1.529/2007 e, Faxinais e Reservas Florestais Legais (RFLs) (PARANÁ, 1993).

A Lei 59/91 (IAP, 1991) é específica ao Meio Ambiente, com foco na ecologia que, segundo o Dicionário Aurélio, tem origem grega derivando das palavras "Oikos", que significa casa e "Logos", que significa estudo, chamou-se de Lei do ICMS Ecológico, também conhecido pela sigla ICMS-e, e trata-se de um instrumento de política pública para compensação financeira aos municípios que abrigam em seus territórios de UC e mananciais.

\subsection{Definições das Areas de Preservação Ambiental}

As UC, definida pelo Ministério do Meio Ambiente (BRASIL, 2006) como sendo espaços territoriais, com características naturais relevantes, incluindo seus recursos ambientais, tendo por função preservar amostras significativas das diferentes populações, habitats e ecossistemas do território nacional e das águas jurisdicionais, para preservação do patrimônio biológico dividindo-se em dois grupos distintos: Unidades de Proteção Integral nas quais o objetivo principal é a proteção da natureza e compreendem as Estações Ecológicas, Reservas Biológicas, Parques, Monumentos Naturais e Refugio de Vidas Silvestres; Unidades de Uso Sustentável nas quais se visa conciliar a conservação da natureza com o uso sustentável. Incluem-se nesta designação as Áreas de Relevante Interesse Ecológico, a Floresta Nacional, Reserva de Fauna, Reserva de Desenvolvimento Sustentável, Reserva Extrativista, Área de Proteção Ambiental (APA) e RPPN (ANTUNES, 2005);

Áreas de Manancial de Abastecimento Público, definidas pelo MMA (BRASIL, 2006), compreendem as fontes de água doce superficiais ou subterrâneas utilizadas para consumo humano ou desenvolvimento de atividades econômicas; Terras Indígenas, definidas pela CF em seu Art. 231, parágrafo primeiro como sendo “... as terras tradicionalmente ocupadas pelos índios e por eles habitadas em caráter permanente..." (BRASIL, 1988);

As RPPN que, segundo o MMA, é uma categoria de UC criada em área privada de forma voluntaria em caráter perpétuo e instituída pelo poder público, dependente da vontade do proprietário, que define a área a ser instituída; Reserva Legal, área localizada no interior de uma propriedade ou posse rural, equivalente a no mínimo $20 \%$ da área total, com a função de assegurar o uso econômico de forma sustentável dos recursos naturais, auxiliar a 
conservação e a reabilitação dos processos ecológicos e da biodiversidade, abrigando fauna silvestre e flora nativa, definidas pela Lei $1 \mathrm{n}^{\mathrm{o}}$ 12.651/2012 (BRASIL, 2012);

Faxinais, definidos pelo IAP (2012), como sendo comunidades camponesas tradicionais em regiões de florestas de Araucária, que fazem uso coletivo da terra para produção de animais e conservação ambiental.

\subsection{Critérios para enquadramento dos municípios para a obtenção do ICMS-e}

No estado do Paraná, o ICMS-e referente a Mananciais de Abastecimento Público é gerenciado pelo Instituto das Águas do Paraná (ÁGUASPARANÁ) e o referente às UC e outras Áreas Protegidas, pelo Departamento de Unidades de Conservação da Diretoria de Biodiversidade e Áreas Protegidas, do IAP (SEMA, 2008), que estabelecem os critérios e condições necessários para que os municípios possam ser enquadrados como beneficiários do ICMS-e, mediante avaliação qualitativa e quantitativa das áreas de preservação.

A quantitativa compreende um cálculo determinando o percentual da superfície da área protegida em relação à área total do município na qual se encontra, e a qualitativa avalia a existência de espécies da flora e fauna e identifica os insumos necessários disponíveis para a área protegida objetivando a manutenção e melhoria do seu processo de gestão (LOUREIRO, 1998).

Para obter o enquadramento dentro dos critérios legais estabelecidos, os municípios devem elaborar programas de ações voltados à área ambiental (NADIR JR., SALM e MENEGASSO, 2007).

Inicialmente o Poder Público municipal deve criar a área de preservação mediante aprovação de Lei pelo Poder Legislativo local, qualificando o tipo, se UC ou Manancial e seu domínio, se público ou privado. Em seguida, o município deve elaborar um Plano de Manejo específico para cada UC ou Manancial existente em seu território, o qual consiste em um documento que reúne todas as atividades a ser desenvolvidas para que as áreas possam cumprir sua finalidade principal, qual seja, proteger os ecossistemas que abrigam (IAP, 2014).

Depois de cumpridas as etapas iniciais, o município deve protocolar junto ao órgão competente, AGUASPARANÁ ou IAP (IAP, 2015), conforme o caso, requerimento solicitando o registro de suas UC ou Mananciais, até o dia 30 de abril para que o órgão possa realizar todos os procedimentos pertinentes à inclusão no cadastro, beneficiando o município já no ano seguinte. Não sendo protocolado o requerimento até a data especificada acima, o cadastramento também ocorrerá, entretanto, o benefício somente se dará no início do segundo ano subsequente à solicitação (LOUREIRO, 1997).

\subsection{A Aplicabilidade do ICMS Ecológico}

Se por um lado a Constituição Federal veda a vinculação do repasse do ICMS dos estados para os municípios (BRASIL, 1988), por outro estabelece que até um quarto da receita pertencente aos municípios será distribuído conforme disposição contida em Lei Estadual definindo os critérios para o repasse dos recursos, a qual no estado do Paraná refere-se à Lei do ICMS-e que destina os recursos a partir de programas de ações na área ambiental (CASAROTTO FILHO e PIRES, 2001), sem, contudo, vincular os recursos repassados a essas ações que deram causa ao enquadramento do município como beneficiário do ICMS-e. Compete, desta forma, aos municípios a destinação dos recursos recebidos. 
Para que os municípios possam desenvolver-se, faz-se necessário o fomento na economia para a geração de ICMS, em volumes necessários para a manutenção de suas atividades estatais, por meio de investimentos na produção, gerando crescimento de forma ordenada para que não haja degradação ambiental (DERANI, 2008).

O mecanismo do ICMS-e por gerar receita aos municípios detentores de áreas de preservação, limitadoras de atividades econômicas, torna-se uma oportunidade de desenvolvimento sustentável fomentando programas de educação ambiental (NADIR JR, SALM e MENEGASSO, 2007), servindo ainda de estímulo à melhoria da qualidade das áreas de preservação existentes, e possibilitando a criação de novas unidades em seu território.

Perusso e Gaio (2012) apontam que o município de Chopinzinho (PR), possui em seu território UC, na categoria Reserva Indígena e Manancial de Abastecimento Público, e os recursos advindos do ICMS-e no período de 2005 a 2011 foram destinados a ações ambientais na Reserva Indígena ATI-Mangueirinha, uma das origens do benefício, traduzindo-se em melhorias da UC e na qualidade de vida de seus habitantes, justificando a evolução dos índices ambientais da Reserva com o consequente aumento do repasse do ICMS-e, contribuindo para o crescimento econômico do município pela ampliação da receita.

Também o município de Maringá, localizado na região noroeste do Estado, o valor dos recursos percebidos via ICMS-e devido à existência de UC em seu território, destinam-se exclusivamente à área ambiental, cobrindo parcialmente as despesas com a manutenção dos parques e a alimentação de animais do Parque do Ingá (LEONARDO; OLIVEIRA, 2007).

No entanto, conforme enfatiza Varela (2012), em estudo sobre a aplicabilidade do ICMS-e no município de Planalto (PR), o município recebe repasses do ICMS-e beneficiado pela existência de Manancial de Abastecimento em seus domínios, sem, contudo, direcionalos ao meio ambiente, visto que a não vinculação dos recursos a ações ambientais possibilita aos gestores o uso indiscriminado destes valores recebidos em diferentes áreas não relacionadas diretamente a questões ambientais.

Neste mesmo sentido, estudo de Mezzomo, Santos e Almeida (2013) sobre as RPPNs localizadas no Município de Luiziana (PR), constata que a conservação da natureza nas UC criadas não está recebendo a atenção devida, evidenciando sua criação apenas com o intuito da geração de receita por meio do ICMS-e, porém, não participam de ações ou projetos de conservação, não contando sequer com planos de manejo.

\subsubsection{Município de Piraquara e municípios vizinhos}

O Município de Piraquara, situado na Região Metropolitana de Curitiba (RMC), cuja localização geográfica é de divisor entre o Primeiro Planalto e o Litoral Paranaense, posicionado na encosta oeste da Serra do Mar, a uma altitude média de $897 \mathrm{~m}$., possui uma população aproximada de 102.798 habitantes (IBGE, 2014). A extensão territorial do Município é de 227,04 Km², dos quais, 208,1 Km², representando 91,66\% de seu território, são ocupados por mananciais de abastecimento público de água, compostas por 1.162 nascentes. As bacias hidrográficas dos rios Iraí, Iraizinho, Itaqui e Piraquara, abrigando ainda 03 reservatórios para abastecimento público, as barragens do Iraí, Piraquara e Piraquara II, responsáveis pelo abastecimento de, aproximadamente, 50\% da população da RMC (TIERA, 2014; IBGE, 2014).

Segundo as fontes, nos 8,34\% restantes da área territorial do município, equivalentes a $18,94 \mathrm{Km}^{2}$, encontram-se as UC representadas pelo Parque Estadual do Marumbi e o Parque Estadual da Serra da Baitaca, além da Floresta Estadual Metropolitana. Da análise 
dos dados apresentados, extrai-se com segurança, que o município de Piraquara (Figura 3) é altamente dependente do ICMS-e, tendo o meio ambiente como principal fonte de receitas para sua manutenção (PIRAQUARA, 2014).

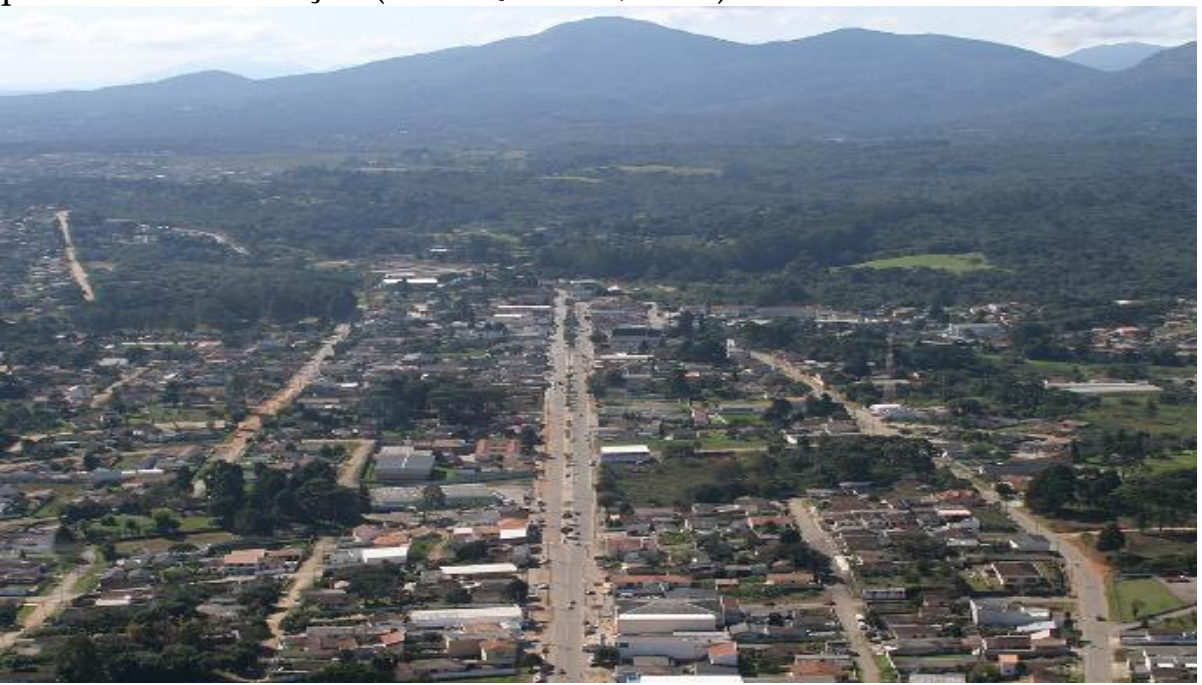

Figura 3. Vista aérea da cidade de Piraquara. (Adaptado de: Cidade-Brasil, 2008)

Destaca-se que o valor do repasse de ICMS do estado ao município no ano de 2014 alcançou o valor de $\mathrm{R} \$ 34.359 .389,76$ e, destes, $\mathrm{R} \$ 18.790 .727,43(54,69 \%)$ corresponde ao ICMS-e, colocando o município na primeira posição no ranking dos municípios beneficiados pelo mecanismo do ICMS ecológico do estado, de acordo com dados obtidos junto à SEFA/AGUASPARANÁ (IAP, 2015).

Para avaliar a aplicabilidade dos recursos oriundos do ICMS-e no município, pesquisou-se junto a $\mathrm{SMMU}^{8}$ e constatou-se que a SMMU encontra dificuldades para a realização de suas atividades, inicialmente pela limitação de recursos humanos na Secretaria que, excluindo a fiscalização, conta com apenas dois servidores, além da Secretária Municipal, para a execução das tarefas burocráticas cotidianas, dificultando o desenvolvimento de projetos necessários para uma boa gestão ambiental.

Outra constatação refere-se aos problemas encontrados pelo município com as invasões, que são ocupações desordenadas nas áreas rural e urbana e contribuem significativamente para a degradação ambiental.

As ocupações irregulares não dispõem da infraestrutura mínima compreendida pelo abastecimento de água tratada, fornecimento de energia elétrica, saneamento básico e coleta de lixo, fazem-no de forma clandestina, o que além de não contribuir para a arrecadação dos Tributos Municipais, por não ser computados pelo SNIS9 como habitantes, também não geram a receita oriunda do Fundo de Participação dos municípios, do Governo Federal. Para exemplificar, a invasão da área conhecida como Guarituba (Figura 4) abriga, aproximadamente, o equivalente a $50 \%$ do total de habitantes das áreas regulares do município de Piraquara (PR).

\footnotetext{
${ }^{8}$ SMMU - Secretaria Municipal de Meio Ambiente e Urbanismo

9 SNIS - Sistema Nacional de Informações Sanitárias -
} 


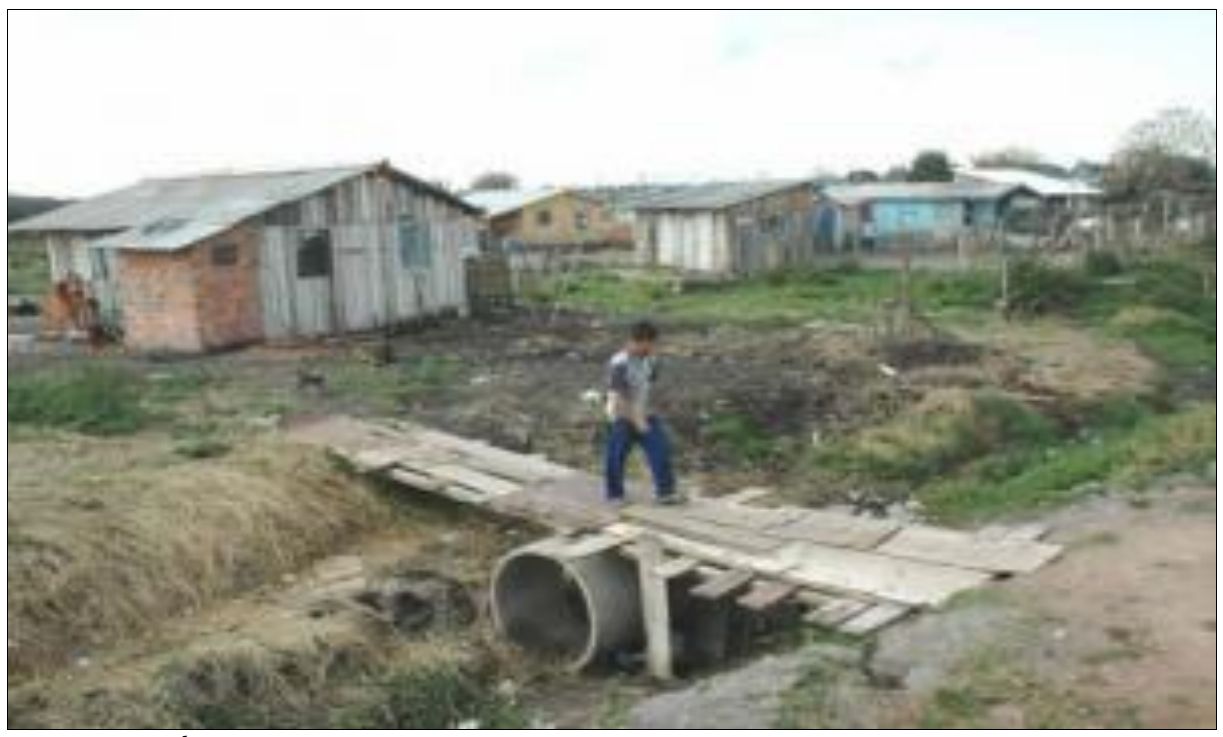

Figura 4. Área de invasão no Guarituba, Piraquara, PR. (Adaptado de: CMI Brasil, 2012).

A prevenção das ocupações irregulares requer fiscalização atuante e permanente, o que é dificultado pelo reduzido quadro de fiscais ambientais e limitação dos recursos destinados à SMMU. A participação dos moradores da área rural nas proximidades do manancial e periféricas à sede do município torna-se importante pois realizam denuncias das ocupações irregulares iniciadas, permitindo as ações da fiscalização, que conta com apoio da força policial para realiza-las.

Um instrumento importante para a preservação ambiental vem sendo desenvolvido no estado e o município de Piraquara (PR) é utilizado como embrião. Trata-se do PPSA ${ }^{10}$ (PARANÁ, 2012).

Por remunerar os pequenos produtores rurais que destinem parte de suas terras para fins de preservação, conservação e recuperação do meio ambiente e dos recursos hídricos mediante contrato de pagamento pelo reconhecimento da prestação de serviços ambientais, coloca o proprietário rural na condição de agente do meio ambiente, colaborando com a fiscalização, realizando denuncias de irregularidades ocorridas na sua região.

Ainda segundo Tiera (2014), os programas de preservação dos Mananciais requer a coparticipação dos demais municípios que circundam a área, dentre eles, Campina Grande do Sul, Colombo, Pinhais, Quatro Barras e São José dos Pinhais (Figura 5), em cujos territórios encontram-se nascentes, córregos e rios que abastecem o Manancial de Abastecimento de Piraquara, pois, ocorrendo a degradação destes, acarretará perda da qualidade das águas do Manancial e a consequente redução do repasse do ICMS-e para o Município (PIRAQUARA, 2007).

${ }^{10}$ PPSA - Programa de Pagamento por Serviços Ambientais 


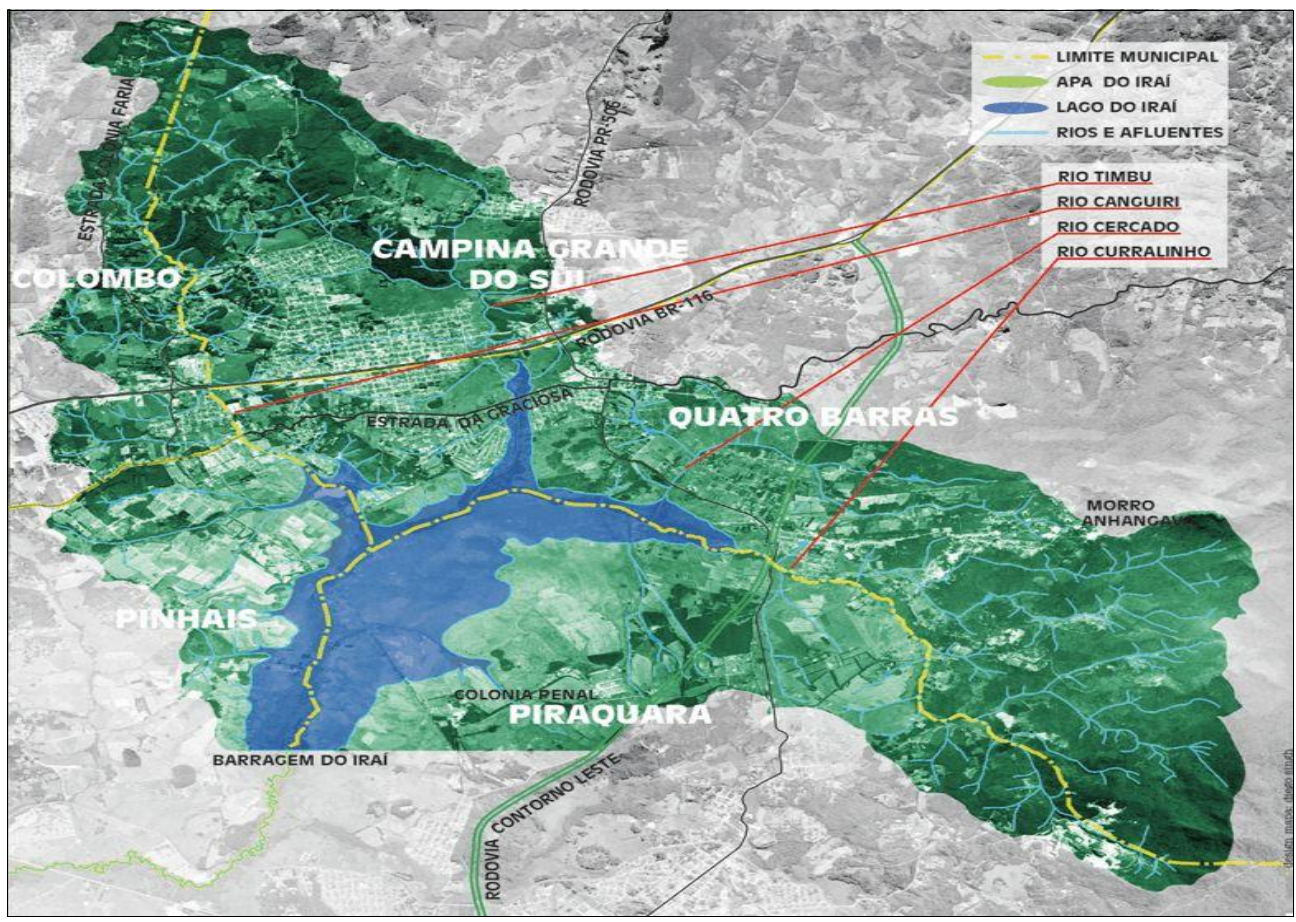

Figura 5. Mapa da APA do Iraí. (Adaptado de: MATER NATURA, 20??).

Verifica-se pelos dados coletados que os poderes executivo e legislativo municipal negligenciam o Meio Ambiente, na medida em que não canalizam recursos oriundos do ICMS-e a ações ou programas que visem a preservação de seu maior patrimônio e fonte de receita financeira, o que poderá contribuir para uma redução de arrecadação futura em virtude do provável comprometimento da qualidade dos mananciais existentes em seu território.

\section{Conclusão}

Nas últimas décadas a degradação do meio ambiente tem causado preocupações, mobilizando nações, motivando Conferências Internacionais, Reuniões de Cúpulas, Simpósios, entre outros, nas quais Tratados, Acordos, Agendas e Protocolos de Intenções são firmados no intuito de mobilizar a sociedade como um todo, conscientizando-as das consequências da degradação, da importância da preservação do que restou e da necessidade premente de agir de modo a possibilitar a regeneração do Meio Ambiente.

Como consequência da preocupação global, governantes de todas as nações tem dedicado técnicos e especialistas na elaboração de mecanismos regulatórios e instrumentos legais que objetivam a preservação ambiental e a consequente melhora na qualidade de vida do ser humano, em harmonia com a natureza.

Com a assunção de compromissos internacionais originados nas discussões sobre o Meio Ambiente, vasta legislação ambiental foi elaborada nas esferas federal, estadual e municipal, como o ICMS-e instituído no Paraná, importante mecanismo de compensação financeira aos municípios detentores de áreas de preservação ambiental de interesse público em seus territórios. Contudo, não basta legislar, se faz necessário aplicar de forma efetiva a legislação ambiental existente por meio de Políticas Públicas que contemplem a educação e conscientização ambiental para engajar os gestores públicos e a população em ações concretas. 
Constatou-se que alguns municípios beneficiados com o ICMS-e, como os exemplos de Maringá e Chopinzinho, aplicam a sua totalidade ou grande parcela do valor arrecadado em prol do meio ambiente, melhorando a qualidade das áreas existentes. Entretanto, a maioria dos municípios paranaenses não destinam recursos do ICMS-e a ações ambientais, entre os quais, Piraquara que tem no ICMS-e sua principal fonte de receitas.

Sugere-se que os gestores municipais conscientizem-se da importância da preservação do Meio Ambiente e dos benefícios do ICMS-e, destinando parcela significativa e suficiente desses recursos a ações efetivas de proteção ambiental, através de programas de educação sócio ambiental voltado à população, implantação de sistema de saneamento básico, ações de recuperação de áreas degradadas, combate a ocupações irregulares e planejamento urbanístico para o desenvolvimento sustentável, por meio da inserção na Lei de Diretrizes Orçamentárias - LDO e na Lei Orçamentária Anual - LOA quando da elaboração do orçamento municipal, de forma a assegurar a preservação de seu maior patrimônio, gerador de vida, receitas e bem estar social.

\section{Referências Bibliográficas}

AGM - Associação Goiana de Municípios. A divisão do ICMS nos Estados Federados. Goiânia, GO. 2013. Disponível em: <http://www.agm.go.org.br/agenciaagm/noticias/item/download/46_b28fd8842790d0b337545d8bc2916c2>.

ANTUNES, P.B., Direito Ambiental, Rio de Janeiro, Lúmen Júris, 2005. Disponível em: http://www.icmsecologico.org.br/index.php?option=com content\&view=article\&id=51\&Itemid=81> acesso em 14/03/2015.

BRASIL. Ministério do Meio Ambiente. Cidades Sustentáveis - Águas na Cidade - Mananciais. 2006. Disponível em: <http://www.mma.gov.br/cidades-sustentaveis/aguas-urbanas/mananciais $>$. Acesso em: 15 mar 2015.

Ministério do Meio Ambiente. Conferência de Estocolmo. Disponível em: http://webcache.googleusercontent.com/search?q=cache:gSwRNiZh260J:www.mma.gov.br/estruturas/ agenda21/_arquivos/estocolmo.doc $+\& c d=1 \&$ hl=pt-BR\&ct=clnk\&gl=br e acessado em 10 fev 2015.

Lei no 6.938/1981. Disponível em: www.planalto.gov.br/ccivil_03/Leis/L6938.htm e acessado em 10 fev 2015.

1988. Constituição da República Federativa do Brasil. Art. 158. Brasília, DF: Senado, 1988. Disponível em <http://www.jusbrasil.com.br/topicos/10665434/artigo-158-da-constituicao-federal-de1988>. Acesso em: 10 fev 2015.

1988. Constituição da Republica Federativa do Brasil. Art. 167. Brasília, DF: Senado, 1988. Disponível em: <http://www.jusbrasil.com.br/topicos/10662220/art-167-da-constituicao-federal-de1988>. Acesso em: 10 fev 2015.

1996. Lei Complementar no 87/1996. Presidência da Republica. Casa Civil. Brasília, DF. 1996. Disponível em: < http://www.planalto.gov.br/ccivil 03/leis/lcp/lcp87.htm>. Acesso em: 08 abr 2015.

1999. Protocolo de Kyoto. Disponível em http://www.mct.gov.br/upd_blob/0012/12425.pdf e acessado em 05 mai 2015.

2000. Lei no 9.985/2000. Presidência da Republica. Casa Civil. Brasília, DF. 2000. Disponível em: $<$ http://www.planalto.gov.br/ccivil_03/leis/19985.htm>. Acesso em: 08 abr 2015. 
2009. Lei no 12.187/2009. Presidência da Republica. Casa Civil. Brasília, DF. 2009. Disponível em: <http://www.planalto.gov.br/ccivil_03/_ato2007-2010/2009/lei/112187.htm>. Acesso em: 28 abr 2015.

2012. Sobre a Rio +20. Disponível em: http://www.rio20.gov.br/sobre_a_rio_mais_20.html e acessado em 10 mai 2015.

2012. Lei no 12.651/2012. Presidência da Republica. Casa Civil. Brasília, DF. 2012. Disponível em: <http://www.planalto.gov.br/ccivil 03/ 2011-2014/2012/lei/112651.htm>. Acesso em: 08 abr 2015.

CASAROTTO FILHO, N.; PIRES, L.H. Redes de pequenas e médias empresas e desenvolvimento local: estratégias para a conquista da competitividade global com base na experiência italiana. $2^{\underline{a}}$ ed. São Paulo: Atlas, 2001.

CIDADE-BRASIL. Foto de Piraquara. Piraquara, 2008. Disponível em: <http://www.cidadebrasil.com.br/foto-piraquara.html>. Acesso em 07 mai 2015.

CMI-B rasil. Centro de Mídia Independente. Moradores do Jardim Guarituba estão ameaçados de despejo por ação movida pelo Ministério Público. Disponível em: $<$ http://www.midiaindependente.org/pt/red/feature/archive128.shtml $>$.

CTN - CÓDIGO TRIBUTÁRIO NACIONAL. 2010. Disponível em: http://www.portaltributario.com.br/obras/ctn.htm e acesso em 10 mai 2015.

DANTAS, M.L. Biodiversidade. O que é biodiversidade. Brasil, 2010. Disponível em: $<$ http://malludantas.blogspot.com>. Acesso em: 10 mai 2015.

DERANI, C. Direito ambiental econômico. São Paulo, Saraiva, 2008.

DINIZ, E.M. os resultados da RIO +10. Revista do Departamento de Geografia, 15 (2002) 31-35. Disponível em: http://www.geografia.fflch.usp.br/publicacoes/RDG/RDG_15/31-35.pdf e acessado em 09 abr 2015.

FREITAS, E. Biodiversidade. Brasil Escola. Brasília, 20??. Disponível em: <http://www.brasilescola.com/geografia/biodiversidade.htm>. Acesso em: 07 abr 2015.

GOMES, E.; DOMINGOS, C. A importância da utilização do ICMS Ecológico pelos Estados. ICMS Ecológico. Artigos. Disponível em: <http://www.icmsecologico.org.br/images/artigos/a056.pdf $>$. Acesso em: 22 nov 2014.

IAP - Instituto Ambiental do Paraná. Lei Complementar no 59/1991. Disponível em: $<$ http://www.iap.pr.gov.br/arquivos/File/Legislacao ambiental/Legislacao estadual/LEIS/LEI COMP LEMENTAR 59 1991.pdf $>$.

Conceito de ICMS Ecológico. Disponível em: <http://www.iap.pr.gov.br/modules/conteudo/conteudo.php?conteudo=419>. Acesso em 22 out 2014.

IAP promove reunião pública para registrar áreas de faxinais. Paraná, 2012. Disponível em: $<$ http://www.itcg.pr.gov.br/modules/noticias/article.php?storyid=304>. Acesso em: 02 abr 2015.

Planos de Manejo. Paraná 2014. Disponível em: <http://www.iap.pr.gov.br/modules/conteudo/conteudo.php?conteudo=1201> Acesso em 02 abr 2015.

IAP - Instituto das Águas do Paraná. Programa do governo do estado, água no campo. Disponível em: http://www.aguasparana.pr.gov.br/ e acessado em 02 abr 2015.

IBGE - Instituto Brasileiro de Geografia e Estatística. Brasil, Censo 2010. Disponível em: $<$ <ttp://www.ibge.gov.br/estadosat/perfil.php?sigla=pr>. Acesso em: 28 abr 2015.

LEONARDO, V.S; OLIVEIRA, A.C. ICMS Ecológico: uma iniciativa dos governos estaduais para a preservação ambiental. Revista Enfoque: Reflexão Contábil. V.26 n.2. ISSN 1984-882X. Maringá. 2007. 
Disponível em: <http://eduem.uem.br/ojs/index.php/enfoque/article/view/4820/3622>. Acesso em: 19 abr 2014.

LOUREIRO, W. ICMS Ecológico: Incentivo econômico à conservação da biodiversidade (Uma experiência exitosa no Brasil). Revista de Administração Municipal, Curitiba, v.44, n. 221, p.49-60, abr./dez. 1997.

ICMS Ecológico em Perguntas e Respostas. Paraná 1998. Disponível em: $<\mathrm{http} / /$ www.tributoverde.com.br/site/modules/mastop_publish/files/files_4901f659c5f56.pdf $>$.Acesso em: 14 mar 2015.

Contribuição do ICMS Ecológico à Conservação da Biodiversidade no Estado do Paraná. Curitiba 2002. Disponível em: <http://www.floresta.ufpr.br/posgraduacao/seminarios/wilson/contribuicao_do_icms.pdf>. Acesso em: 18 mar 2015.

O ICMS - Ecológico na biodiversidade. Disponível em: $<$ http://www.ambientebrasil.com.br/composer.php3?base=./snuc/index.html\&conteudo=./snuc/ artigos/icmsm.html>. Acesso em: 14 mar 2015.

MAPASDOMUNDO. Imagens do Paraná. Disponível em: <http://mapasdomundo.tk/wpcontent/uploads/2013/08/mapa-do-parana-3-.gif >. Acesso em: 04 mai 2015.

MATER, Natura. Instituto de Estudos Ambientais. Mapa da APA do Iraí. Curitiba, PR. 20??. Disponível em: <http://www.maternatura.org.br/prolango/mapapairaibig.htm>. Acesso em: 04 mai 2015

MEZZOMO, M.M; SANTOS, B.P; ALMEIDA, J.A. Relação entre criação de RPPNs e geração de ICMS ecológico: Estudo sobre Luiziania - PR. Revista Perspectiva Geográfica, V.8, N.9, 2013. Disponível em: $<$ http://e-revista.unioeste.br/index.php/pgeografica/article/view/9596/7044>. Acesso em: 22 nov 2014.

NADIR JR, A.M.; SALM, J.F.; MENEGASSO, M.E. Estratégias e Ações para a Implantação do ICMS Ecológico por meio da Coprodução do Bem Público. Revista de Negócios, Blumenau, v. 12, n.3, p.62 73, jul/set 2007. Disponível em: <http//proxy.furb.br/ojs/index.php/rn/article/view/632>. Acesso em: 22 nov 2014.

OLIVEIRA, L.D. A Conferência do Rio de Janeiro - 1992 (Eco-92): Reflexões sobre a Geopolítica do Desenvolvimento Sustentável. 2012. Disponível em: http://www.anppas.org.br/encontro6/anais/ARQUIVOS/GT15-170-31-20120626115525.pdf e acessado em 15 mai 2015.

PARANÁ, 1993. Lei Complementar Estadual no 67/1993. Curitiba, PR: ALEP, 1993.

1996. Decreto Estadual no 2.791/96. Curitiba, PR, 1996. Disponível em: $<$ http://www.tributoverde.com.br/site/modules/mastoppublish/files48fe1c89a55ee.pdf $>$. Acesso em 14 mai 2015

2012. Lei Estadual no 17.134. Bioclima Paraná. 2012. Disponível em: http://www.bioclima.pr.gov.br/modules/conteudo/conteudo.php?conteudo=21 e acessado em $10 \mathrm{abr}$ 2015 Curitiba, PR. 2[???], Secretaria de Estado do Meio Ambiente e Recursos Hídricos. ICMS-ECOLÓGICO
no
Paraná.
Disponível
em:

$<$ http://www.meioambiente.pr.gov.br/modules/conteudo/conteudo.php?conteudo=246>. Acesso em 08 nov 2014.

PERUSSO, A.; GAIO, D. ICMS Ecológico: forma de aplicação do recurso na reserva ATIMangueirinha no Município de Chopinzinho - PR. UTFPR. Pato Branco, 2012. Disponível em: $<$ http://bibliotecadigital.pb.utfpr.edu.br/bibiotecadigital/index.php/ecap/article/view/2077/894>.

Acesso em: 19 abr 2015. 
PIRAQUARA, 2007. LEI no 907/2007. Camara Municipal de Piraquara. Piraquara, PR. 2007. Diponivel em: <https://www.leismunicipais.com.br/a/pr/piraquara/lei-ordinaria/2007/90/907/lei-ordinaria-n-9072007-dispoe-sobre-o-codigo-municipal-do-meio-ambiente-do-municipio-de-piraquara-e-da-outrasprovidencias.html>. Acesso em: 26 abr 2015.

2014. Lei no 1.427/2014. Camara Municipal de Piraquara. Piraquara, PR. 2014. Disponível em: <http://www.diariomunicipal.com.br/amp/materia/1743929>. Acesso em 26 abr 2015.

SCAFF, Fernando F.; Tupiassu. Lise V. da C. Direito tributário ambiental - Tributação e políticas públicas: O ICMS ecológico. São Paulo: Malheiros Editores Ltda, 2005.

SEMA. Resolução SEMA no 41/2014. Secretaria de Estado do Meio Ambiente e Recursos Hídricos. Paraná 2014.

ICMS-ECOLÓGICO no Paraná. Compilação da Legislação do ICMS Ecológico por Biodiversidade. Secretária de Estado do Meio Ambiente e Recursos Hídricos. Paraná 2008. Disponível em: <http://www.meioambiente.pr.gov.br/modules/conteudo/conteudo.php?conteudo=246>. Acesso em: 08 nov 2014.

TIERA, G. Cartilha de Controle e Educação Ambiental. Secretaria Municipal de Meio Ambiente e Urbanismo. Prefeitura Municipal de Piraquara. Piraquara, PR. 2014.

VARELA, R.F. Estudo do Cenário Ambiental Vinculado ao ICMS Ecológico. O Professor PDE e os Desafios da Escola Pública Paranaense. Secretaria de Estado de Educação. Paraná, 2012. Disponível em:

$<$ http://www.diadiaeducacao.pr.gov.br/portals/cadernospde/pdebusca/producoes pde/2012/2012 uni oeste_geo_artigo_roseli_fatima_varela.pdf $>$. Acesso em: 11 abr 2015.

WWF-Brasil. Lei 792/2007. Diretrizes para a Política Nacional de Pagamentos Por Serviços Ambientais. Brasília, DF. 2014.2 Disponível em: $<$ http://www.observatorioflorestal.org.br/sites/default/files/diretrizes_pnpsa_final.pdf $>$. Acesso em: 08 abr 2015. 